\title{
PENGARUH SENAM KAKI DIABETES DENGAN BOLA PLASTIK TERHADAP PERUBAHAN KADAR GULA DARAH PADA PASIEN DIABETES MELLITUS TIPE 2
}

\author{
Effects of Diabetes Foot Gymnastics with Plastic Balls on Changes in Blood Sugar \\ Levels in Type 2 Diabetes Mellitus Patients
}

\author{
Maelina Ariyanti ${ }^{1}$, Hapipah $^{2}$, Heri Bahtiar ${ }^{3}$, Risma Ayu $^{4}$ \\ ${ }^{I}$ Departemen Keperawatan Medikal Bedah, STIKES Yarsi Mataram, Mataram, NTB, Indonesia \\ ${ }^{2}$ Departemen Keperawatan Komunitas, STIKES Yarsi Mataram, Mataram, NTB, Indonesia \\ ${ }^{3}$ Departemen Manajemen Keperawatan, STIKES Yarsi Mataram, Mataram, NTB, Indonesia \\ ${ }^{4}$ Program Studi S1 Keperawatan, STIKES Yarsi Mataram, Mataram, NTB, Indonesia \\ Korespondensi : maelinaariyanti83@gmail.com
}

\begin{abstract}
ABSTRAK
Diabetes mellitus telah menjadi penyebab kematian terbesar ke-4 di dunia. Diperkirakan diabetes mellitus meningkat setiap tahunnya menjadi 333 juta. Diabetes Mellitus Tipe 2 terjadi akibat penurunan sensitivitas terhadap insulin (resistensi insulin) atau akibat penurunan jumlah produksi insulin. Pencegahan yang dapat dilakukan untuk mengurangi komplikasi, salah satu pilar penatalaksaan diabetes adalah latihan jasmani atau olahraga yaitu senam kaki diabetes dengan bola plastik. Penelitian ini bertujuan untuk mengetahui pengaruh senam kaki diabetes dengan bola plastik terhadap perubahan kadar gula darah pada pasien diabetes mellitus tipe 2 di lingkungan Geguntur wilayah kerja Puskesmas Karang Pule. Desain penelitian yang digunakan adalah pra eksperimental dengan one group pre test post test design. Teknik pengambilan sampel dilakukan dengan total sampling dengan jumlah sampel 20 orang. Hasil penelitian menggunakan uji t-test paired sampel test didapatkan nilai $p=0,000<\mathrm{a}=0,05$. Kesimpulan hasil penelitian menunjukkan adanya pengaruh senam kaki diabetes dengan bola plastik terhadap perubahan kadar gula darah pada pasien diabetes mellitus tipe 2 di lingkungan Geguntur wilayah kerja puskesmas Karang Pule. Rekomendasi yang dapat diberikan adalah pemberian kegiatan senam kaki diabetes yang teratur di pelayanan kesehatan untuk mencegah atau mengurangi komplikasi diabetes mellitus tipe 2 .
\end{abstract}

Kata kunci : kadar gula darah, senam kaki diabetes, diabetes mellitus tipe 2

\section{ABSTRACT}

Diabetes mellitus has been fourth leading cause of death in the world. It is estimated that the number of diabetes mellitus increases every year to 333 million. Diabetes mellitus result type 2 occur because of decreasing ability of sensitivity to insulin (insulin resistance) or due to a decreasing insulin production. Prevention can be done to reduce the complications, one way of diabetes management is physical exercise, that exercise is foot gymnastics using plastic ball. The aim of this research is to determine the influence of diabetic foot gymnastics using plastic ball toward decreasing of blood sugar levels in diabetes mellitus type 2 in Geguntur working area of Karang Pule Public Health Center. The research design used in this research is pre experimental with one group pre test post test design. The sampling technique used in this research is total sampling with 20 samples. The result of this research is $t$-test paired sample test obtained that $p$ value $=0,000<\grave{a}=0,05$. The conclusion of the research showed that the influence of diabetic foot gymnastics using plastic ball toward decreasing of blood sugar levels in diabetes mellitus type 2 in Geguntur working area of Karang Pule Public Health Center. Researcher can suggest that patients suspected of diabetes mellitus type 2 should provide foot gymnastic activities regularly in health care to prevent or reduce the complications of the diabetes mellitus type 2.

Keywords : blood sugar level, foot gymnastics of diabetes, diabetes mellitus type 2 


\section{PENDAHULUAN}

Diabetes Mellitus (DM) merupakan salah satu penyakit metabolik yang menyebabkan kerusakan secara progresif sel beta pankreas dan penurunan sensitivitas sel tubuh terhadap insulin tanpa diawali oleh proses autoimun (suyono,2013). Secara global jumlah penderita DM terus meningkat. Pada tahun 2025 diperkirakan meningkat menjadi 333 juta jiwa. Menurut WHO memperkirakan 194 juta jiwa (5.1\%) dari 3.8 milyar penduduk usia 20-79 tahun menderita DM. Berarti ada 1 orang per 10 detik atau 6 orang permenit yang meninggal akibat penyakit yang berakitan dengan diabetes. Sedangkan menurut American Diabetes Association (ADA) setiap 21 detik ada 1 orang yang terkena diabetes (ADA, 2013). Prevalensi DM akan terus meningkat seiring dengan perubahan pola hidup dan komplikasi dapat muncul salah satunya adalah neuropati DM yang dapat mengenai seluruh saraf tubuh baik saraf sensorik, motorik dan otonom (Quan, 2104).

Berbagai komplikasi dapat muncul pada pasien DM, salah satunya adalah neuropati DM hiperglikemia kronis dapat menyebabkan gangguan pada aktivitas jalur poliol (glukosa-sorbitol-fruktosa) sehingga terjadi penimbunan sorbitol dan fruktosa di dalam sel saraf). Penimbunan ini menyebabkan edema sel saraf serta memicu stimulasi berbagai enzim yang dapat merusak sel saraf baik melalui faktor metabolik dan faktor neurovaskular. Gangguan metabolik yang di stimulasi oleh penimbunan sorbitol dan fruktosa tersebut dapat secara langsung ataupun tidak langsung merusak sel saraf. Gangguan neurovaskular yang terjadi akan mengganggu suplai darah dan oksigen menuju sel saraf. Kerusakan sel saraf akibat DM atau neuropati DM dapat mengenai seluruh saraf tubuh baik serat saraf sensorik, motorik, dan otonom (Quan, 2014). Kerusakan serabut saraf sensorik akan menyebabkan gangguan sensasi rasa getar, rasa sakit, rasa kram, semutan, rasa baal, ransang ternal atau suhu, dan hilangnya reflex tendo pada kaki sehingga akan menyebabkan gangguan mekanisme protektif pada kaki. Saraf sensorik ini merupakan system saraf yang pertama kali terganggu pada diabetes mellitus sebelum sistem saraf motorik dan otonom.

Senam kaki diabetes adalah kegiatan atau latihan yang dilakukan dengan menggerakkan otot dan sendi kaki. Salah satu media yang digunakan adalah bola plastik dimana meletakkan bola plastik dilantai dan pasien diabetes mellitus diperintahkan untuk menginjak bola plastik tersebut dilakukan satu kali dalam sehari, ini bertujuan untuk memberikan rangsangan yang dapat membuat rileks dan melancarkan peredaran darah. Lancarnya peredaran darah karena dipijat, memungkinkan darah mengantar lebih banyak oksigen dan gizi ke sel-sel tubuh, sekaligus membawa lebih banyak racun untuk dikeluarkan. Pijat refleksi yang dilakukan pada telapak kaki terutama di area organ yang bermasalah, akan memberikan rangsangan pada titik-titik saraf yang berhubungan dengan pankreas agar menjadi aktif sehingga menghasilkan insulin melalui titik-titik saraf yang berada di telapak kaki, dimana kaki yang mulanya akral dingin meningkat menjadi lebih hangat, kaki yang kaku menjadi lentur, kaki yang kebas menjadi tidak kebas, dan kaki yang atrofi perlahan-lahan kembali normal (Oktaviah dkk, 2014).

\section{TUJUAN PENELITIAN}

Penelitian ini bertujuan untuk mengetahui pengaruh senam kaki diabetes dengan bola plastik terhadap perubahan kadar gula darah pada pasien Diabetes Mellitus Tipe 2.

\section{METODE PENELITIAN}

Desain

Penelitian ini merupakan jenis preeksperimen dengan pendekatan one group pre test post test design

\section{Populasi dan Sampel}

Populasi penelitian ini adalah seluruh penderita diabetes mellitus tipe 2 yang berada di wilayah kerja Puskesmas Karang Pule. Sampel dalam penelitian ini ditentukan berdasarkan metode total sampling yaitu 
semua psien DM tipe 2 yang berada di wilayah kerja PKM karang Pule yaiutu di lingkungan Geguntur. Jumlah sampel dalam penelitian ini adalah 20. Kriteria inklusi dalam penelitian ini adalah berusia $>30$ tahun, tidak menggunakan insulin, tidak mengkonsumsi obat-obat penurun kadar gula darah, tidak sedang melakukan diet. Kriteria eksklusi dalam penelitian ini adalah tidak absen dalam kegiatan senam kaki diabetes yang telah di programkan, DM tipe 1, tidak toleransi terhadap kegiatan senam, berusia $<30$ tahun $>70$

\section{Tempat dan Waktu Penelitian}

Penelitian ini dilakukan di Puskesmas

Karang Pule Mataram, dengan lama penelitian 16 minggu serta pemberian intervensi selama 2 minggu.

\section{Intervensi}

Responden yang telah memenuhi kriteria peneltian akan diukur kadar gula darah sebelum dilakukan senam kaki diabetes dengan bola plastik pada hari pertama. Selanjutnya dilakukan senam kaki diabetes dengan menggunakan bola plastik 2 kali seminggu selama 2 minggu. Setelah itu pada hari ke-4 diukur kembali kadar gula darah responden untuk melihat apakah ada perubahan atau tidak. Setiap sesi senam dilaksanakan dengan durasi 20-30 menit. Intervensi dilakukan di pagi hari langsung oleh peneliti dengan dibantu oleh petugas PKM yang memegang program DM dan asisten peneliti.

\section{Instrumen dan Prosedur Pengukuran}

Instrument yang digunakan dalam penelitian ini adalah glukometer untuk mengukur kadar gula darah, yang terlebih dahulu sudah terkalibrasi menggunakan kode chip. Instrument lainnya yang digunakan adalah bola plastik sebagai media yang digunakan untuk senam kaki, lembar observasi hasil ukur nilai kadar gula darah, serta cheklist, berisikan data demografi yang harus dipilih responden.

\section{Analisa Data}

Analisa univariat dilakukan pada data karakteristik responden. Analisa bivariat dilakukan menggunakan paired t-test.

\section{HASIL PENELITIAN}

Hasil yang disajikan dalam penelitian ini yaitu sebagai berikut:

Tabel 1

Karakteristik Responden $(\mathrm{n}=20)$

\begin{tabular}{|c|c|}
\hline Variabel & $\mathrm{n}(\%)$ \\
\hline Usia & \\
\hline $50-55$ & $6(30)$ \\
\hline $56-60$ & $11(55)$ \\
\hline $61-65$ & $3(15)$ \\
\hline
\end{tabular}

Jenis Kelamin

Laki-Laki 2(10)

Perempuan 18(90)

Tingkat Pendidikan

$\begin{array}{lr}\text { SD } & 10(50) \\ \text { SMP } & 6(30) \\ \text { SMA } & 4(20)\end{array}$

\begin{tabular}{ll} 
Status Pekerjaan & \\
Bekerja & $10(50)$ \\
Tidak Bekerja & $10(50)$ \\
\hline
\end{tabular}

Berdasarkan Tabel 1 diperoleh informasi yang menunjukkan usia responden lebih dominan pada rentang 56-60 tahun sebanyak 11 orang $(55 \%)$, dengan jenis kelamin sebagian besar perempuan sebanyak 18 orang $(90 \%)$. Tingkat pendidikan responden dididominasi dengan pendidikan SD sebanyak 10 orang $(50 \%)$, serta status pekerjaan yang diketahui sebanyak 10 orang $(50 \%)$ bekerja dan sebanyak 10 orang $(50 \%)$ tidak bekerja.

Tabel 2

Kadar Gula Darah Responden Sebelum dan Sesudah Dilakukan Senam Kaki Diabetes (n=20)

\begin{tabular}{cccccc}
\hline Kadar Gula Darah & Mean & Median & SD & \multicolumn{1}{c}{ Min-Max } & p-value \\
\hline Pre Test & 212.80 & 246.50 & 31.737 & $200-371$ & 0,000 \\
Post Test & 192.15 & 115.00 & 27.685 & $97-123$ & 0 \\
\hline
\end{tabular}


Berdasarkan hasil penelitian, dilihat bahwa rata-rata kadar gula darah sesudah intervensi lebih rendah dibandingkan dengan rata-rata kadar gula darah sebelum intervensi. Hasil analisis didapatkan rata-rata kadar gula darah responden sebelum intervensi sebesar $212.80 \mathrm{mg} / \mathrm{dl}$ dengan standar deviasi $56.686 \mathrm{mg} / \mathrm{dl}$. Glukosa darah terendah $200 \mathrm{mg} / \mathrm{dl}$ dan glukosa tertinggi $371 \mathrm{mg} / \mathrm{dl}$. Rata-rata kadar gula darah sesudah intervensi sebesar $192.15 \mathrm{mg} / \mathrm{dl}$ dengan standar deviasi $9.539 \mathrm{mg} / \mathrm{dl}$. Glukosa terendah $97 \mathrm{mg} / \mathrm{dl}$ dan glukosa tertinggi 123 $\mathrm{mg} / \mathrm{dl}$. Selisih mean kadar gula darah sebelum intervensi dan sesudah intervensi sebesar $20.65 \mathrm{mg} / \mathrm{dl}$. Berdasarkan hasil uji paired sampel $t$ diperoleh nilai $\mathrm{p}=0,000$, yang menunjukkan ada pengaruh senam kaki diabetes dengan bola plastik terhadap perubahan kadar gula darah pada pasien diabetes mellitus tipe 2 di lingkungan Geguntur wilayah kerja Puskesmas Karang Pule.

\section{PEMBAHASAN}

Sebelum diberikan intervensi senam kaki diabetes dengan menggunakan bola plastik rata-rata kadar gula darah responden masih tinggi yaitu $\geq 200 \mathrm{mg} / \mathrm{dl}$ sebanyak 20 orang dengan rata-rata $212.80 \mathrm{mg} / \mathrm{dl}$. Sedangkan setelah diberikan intervensi senam kaki diabetes dengan menggunakan bola plastik kadar gula darah responden menjadi lebih rendah atau turun ke kategori normal $<100 \mathrm{mg} / \mathrm{dl}$ sebanyak 20 orang dengan rata-rata $192.15 \mathrm{mg} / \mathrm{dl}$. Adapun selisih rata-rata kadar gula darah sebesar $20.650 \mathrm{mg} / \mathrm{dl}$. Hal ini sesuai dengan pendapat yang dikemukakan Yanuar (2011) bahwa pada saat latihan (senam kaki) kebutuhan energi meningkat sehingga otot menjadi lebih aktif dan terjadi peningkatan pemakaian glukosa sehingga terjadi penurunan kadar gula darah, hal ini juga dilatarbelakangi oleh faktor kontinuitas atau keteraturan pasien dalam mengikuti senam sehingga terjadi penurunan kadar gula darah.

Tingginya kadar gula darah responden sebelum intervensi dipengaruhi banyak faktor, karakteristik responden yang tergolong lansia (50-70 tahun) dapat mempengaruhi perubahan komposisi tubuh, turunnya aktivitas, perubahan pola makan dan penurunan fungsi neurohormonal, sehingga dapat mempengaruhi kondisi hiperglikemia akibat resistensi insulin yang meningkat. Sedangkan hasil uji statistik dengan menggunakan uji Paired sampel ttes menunjukkan bahwa senam kaki diabetes dengan bola plastik berpengaruh terhadap penurunan kadar gula darah pasien DM tipe 2 di lingkungan Geguntur wilayah kerja Puskesmas Karang Pule Kelurahan Jempong Baru $(\mathrm{p}=0,000, \alpha=0,005)$

Individu yang lebih aktif memiliki kadar gula darah yang lebih rendah dibandingkan yang tidak aktif. Selain itu sesuai dengan pendapat Yunir Dalam Sudoyo (2013) yang menyatakan bahwa kegiatan fisik dinamik yang melibatkan otototot utama akan menyebabkan permeabilitas meningkat pada otot yang berkontraksi, sehingga saat latihan reseptor insulin akan lebih banyak dan lebih peka. Kepekaan reseptor insulin dapat berlangsung 12-24 jam setelah dilakukan senam frekuensi, intensitas, durasi dan jenis kaki diabetes, yang menyebabkan gula darah dapat kembali normal. Senam kaki diabetes dapat berperan dalam pengaturan kadar gula darah bila dilakukan sesuai prinsip-prinsip latihan jasmani. Prinsip senam kaki diabetes yaitu memenuhi standar senam (Santoso, 2014). Frekunsi senam kaki diabetes dalam penelitian ini telah memenuhi standar minimal yaitu dilaksanakan teratur 3 kali seminggu. Hal ini sesuai dengan prinsip senam kaki diabetes yang menyatakan untuk mencapai hasil yang optimal maka latihan harus dilakukan secara teratur 3 kali seminggu dan tidak lebih dari 2 hari berurutan tanpa latihan (American Diabetes Association, 2012).

Perubahan kadar gula darah disebabkan oleh aktivitas/senam yang dilakukan selama 2 minggu dengan 4 kali dilakukan senam kaki diabetes dengan bola plastik secara berkelanjutan sehingga sirkulasi dalam darah meningkat dan terjadi penurunan kadar gula darah pada pasien diabetes mellitus tipe 2. Dan didukung pula oleh kesadaran responden yang meningkat dalam hal memperhatikan pola makan serta lebih memperhatikan latihan seperti senam kaki. 
Hasil penelitian sejalan yang dilakukan oleh Michael Y.Karundeng (2016) dengan menggunakan uji yg sama yaitu paired sampel t-tes dan Septi Farianingsih (2015) dengan menggunakan uji Wilcoxon Signed rank Test diperoleh hasilada pengaruh kuat senam kaki diabetes terhdapa penurunan kadar gula darah pada diabetes tipe 2.

\section{KESIMPULAN}

Implikasi

Hasil penelitian ini menunjukkan efek yang positif terhadap penurunan kadar gula darah setelah pemberian senam kaki diabetes dengan bola plastik terhadap perubahan kadar gula darah pada pasien diabetes mellitus tipe 2. Perubahan kadar gula darah dapat menurun secara konsisten jika latihan dilakukan dengan frekuensi yang sesuai dengan kondisi pasien. Implikasi yang diharapkan dari hasil penelitian ini yaitu dapat menjadi praktik baik dan sumber informasi bagi masyarakat sebagai salah satu cara untuk mengontrol kadar gula darah sehingga masyarakat dapat kombinasi latihan senam kaki dengan bola plastik dengan penggunaan terapi farmakologi.

\section{Keterbatasan}

Pada penelitian ini terapis kurang memperhatikan secara spesifik batas kemampuan responden dalam melakukan latihan dan variabel-variabel lain yang mungkin dapat mengaburkan hasil penelitian ini, sehingga dibutuhkan penelitian lebih lanjut dengan pada variabel lain yang dapat mempengaruhi perubahan kadar gula darah, seperti gaya hidup, penyuluhan, tersedia atau tidak tersedianya fasilitas-fasilitas kesehatan, sikap dan perilaku petugas kesehatan.

\section{DAFTAR PUSTAKA}

American Diabetes Association. (2013). Physical activity/exercise and diabetes. http://www.uhs.wisc.edu/docs/uwhealt h_diabetes_260.

Akhtyo. (2010). Gambaran klinis Hipoglikemia Pada Pasien Diabetes Mellitus. Yogyakarta
Michael Y. Karundeng. (2016). FaktorFaktor yang Mempengaruhi Kualitas Hidup Pasien Diabetes Mellitus Dengan Ulkus Diabetikum. Jorn PSIK

Novitasari, Retno. 2012. Diabetes Mellitus Dilengkapi Dengan Senam DM. Nuha Medika. Yogyakarta

Oktaviah D. Dkk. (2014). Efektifitas Senam Kaki Diabetic Dengan Bola Plastic Terhadap Tingkat Sensitivitas Kaki Pada Pasien Diabetes Mellitus Tipe2

Santoso. (2014). Manajemen Data Untuk Analisis Data Penelitian Kesehatan. Yogyakarta : Gosyen Publishing

Soebagio. (2014). Penatalaksaan Diabetes Mellitus Terpadu. Balai Penerbit FKUI. Jakarta.

Shadine. (2013). Mengenal Penyakit Hipertensi, Diabetes, Stroke, dan Serangan Jantung. Jakarta : Keenbooks

Suyono. Dkk. (2013). Masalah Diabetes di Indonesia. Buku Ajar Ilmu Penyakit Dalam. Jakarta: Pusat Penerbit Departemen Penyakit Dalam FKUI

Suminarti. (2012). Kepatuhan penderita Diabetes Mellitus Tipe II Ditinjau Dari Locus Of Control. J Ilm Psikol Terap

Sunaryo, dan Sudiro. (2014). Pengaruh Senam Diabetic Terhadap Penurunan Resiko Ulkus Kaki Diabetic Pada Pasien Diabetes Mellitus Tipe 2 Di Perkumplulan Diabetik

Tapan, E. (2015). Kesehatan keluarga penyakit degenerative. Jakarta : Elex Medika Komputindo

Tobing. (2016). Care Yourself, Diabetes Mellitus. Jakarta: Penebar Plus

World Health Organization. (2008). Definition, Diagnosis and Classification of Diabetes Mellitus and Its Complication

Yanuar. (2011). Pemantauan Pengendalian Diabetes Mellitus Dalam Soegondo S dkk (eds), Pemantauan diabetes mellitus terpadu. Penerbit FKUI. Jakarta

Zenurokhim, dkk. (2012). Diabetes Mellitus Pada Usia Lanjut, Dalam Sudoyo. Buku Ajar Ilmu Penyakit Dalam. Jakarta : Pusat Penerbit Departemen Penyakit Dalam 